\title{
Composite scintillators for a wide range of problems in detection of ionizing radiation
}

\author{
N.L.Karavaeva \\ Institute for Scintillation Materials, STC "Institute for Single Crystals," \\ National Academy of Sciences of Ukraine, 60 Lenin Ave., 61001 Kharkiv, \\ Ukraine
}

Received August 19, 2014

\begin{abstract}
We have developed a new type of scintillation materials - composite scintillators. It has been shown that such materials can be obtained both on the basis of organic (fast neutron detection) and inorganic (thermal neutron detection) grains. The use of radiationresistant materials and wide range of scintillation materials for preparation of grains allows using such approach not only for radioecology (weak fluxes), but also in high energy physics. The promising results on radiation stability of composite scintillators are preliminary, and further studies are necessary.
\end{abstract}

Разработан новый вид сцинтилляционного материала - композиционные сцинтилляторы. Показано, что данный материал может создаваться как на основе органических (детекторы быстрых нейтронов), так и неорганических (детекторы тепловых нейтронов) гранул. Использование радиационно-стойких основ и любых сцинтилляционных веществ для создания гранул позволяет использовать такой технологический подход не только для задач радиоэкологии (сверхмалые потоки), но и для задач физики высоких энергий. Полученные результаты о радиационной стойкости композиционных сцинтилляторов являются предварительными и указывают на необходимость продолжения исследований данных объектов.

Композиційні сцинтилятори для широкого класу завдань реєстрації іонізуючих випромінювань. Н.Л.Караваєва.

Розробленј новий вид сцинтиляційного матеріалу - композиційні сцинтилятори. Показано, що даний матеріал може створюватися як на основі органічних (детектори швидких нейтронів), так і неорганічних (детектори теплових нейтронів) гранул. Використання радіаційно-стійких основ і будь-яких сцинтиляційних матеріалів для отримання гранул дозволяє використовувати такий технологічний підхід не тільки для задач радіоекології (надмалі потоки), але і для задач фізики високих енергій. Одержані результати про радіаційну стійкість композиційних сцинтиляторів $є$ попередніми i вказують на необхідність продовження досліджень даних об'єктів.

\section{Introduction}

For applications in radioecology, where it is very important to detect very weak fluxes of ionizing radiation, we have developed a new type of scintillation materials - composite scintillators, containing a dielectric gel as a base (matrix), into which grains of scintillating substances were introduced [ 1 , $2]$. It has been shown that such technologi- cal approach allows creation of efficient detectors of various kinds of ionizing radiation, depending on the materials used. In the case of single crystalline organic grains, efficient fast neutron detectors can be obtained, allowing separation of signals from neutrons and background gamma-radiation. Using inorganic single crystalline grains, efficient detectors of thermal neutrons can be obtained. Varying the size of these 
grains allows substantial reduction of the background radiation effects. A possibility was shown of producing scintillators of very large area by means of specially developed methods for assembling separate fragments of the scintillator [3].

With a new generation of accelerators, dose loads on the detectors become much higher. Obtaining information on radiation stability of the new materials can open prospects for creation of scintillation systems with high radioresistance on the basis of composite scintillators.

\section{Composite scintillators for detection of weak fluxes of ionizing radiations}

We made preliminary estimates of the size of crystalline grains of composite scintillators for detection of fast neutrons. Fast neutrons generate recoil protons in the organic material with maximum energy equal to the energy of neutrons. The dimensions of the sensitive scintillation material (grain) should ensure absorption of the recoil proton energy, i.e., the proton free path should not exceed characteristic dimensions of the grains [4]. The free path of a particle in a substance of complex atomic composition can be calculated basing on the reference data [5]. The highest recoil proton energy that can be obtained in the scintillator using a ${ }^{239} \mathrm{Pu}-\mathrm{Be}$ source is $9.7 \mathrm{MeV}$. The calculations show that for detection of recoil protons of such energy the size of grains should be about $2-4 \mathrm{~mm}$.

Composite scintillators that were developed in our laboratory on the basis of stilbene and $p$-terphenyl grains allowed separation of particles by the scintillation pulse shape similarly to organic single crystals [6-8].

For detection of thermal neutrons, we have developed composite scintillators on the basis of gadolinium silicate (Ce:GSO) and pyrosilicate (Ce:GPS) grains [9]. These substances were chosen because of their very high radiation capture cross-section of thermal neutrons by gadolinium nuclides ${ }^{155} \mathrm{Gd},{ }^{157} \mathrm{Gd}$. The secondary emissions due to interaction of thermal neutrons with gadolinium atoms (i.e., emissions generating scintillation signals), correspond to peaks at $33 \mathrm{keV}, 77 \mathrm{keV}$ and $\sim 8 \mathrm{MeV}$ on the gammascintillation scale [10]. The crystalline grains were chosen to be of so small size that they were sensitive practically only to secondary emissions of low energy, i.e., the signals used were from conversion electrons (33 keV) and X-ray radiation (44 keV),

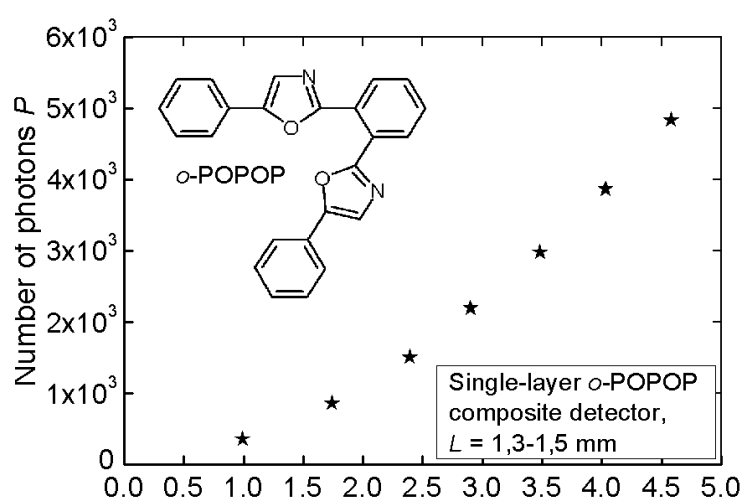

Fig. 1. The scintillation signal as function of alpha-excitation energy for scintillators on the basis of $o$-POPOP.

which corresponded to $65 \%$ of all events. The $33 \mathrm{keV}$ electron free path in Ce:GSO or Ce:GPS grains is approximately $0.002 \mathrm{~mm}$ [11]. We have shown that a single-layer composite scintillator with average Ce:GSO or Ce:GPS grain size of 0.06-0.1 mm can be an efficient selective detector for conversion electrons of $33 \mathrm{keV}$ energy and the total peak of $77 \mathrm{keV}[2,9]$.

We have developed novel combined composite detectors for separate detection of fast and thermal neutrons in the presence of background gamma-radiation. These detectors comprise a single-layer inorganic composite scintillator for detection of thermal neutrons and an organic composite scintillator for detection of fast neutrons [12].

For detection of alpha-particles, even very small grains of organic single crystal can be used. At the same time, the secondary particles - electrons generated by alpha-particles of such energy - have their free path of $\approx 1-1.5 \mathrm{~mm}$. In this case, one has to decrease losses due to light scattering planes, which can be achieved by increasing the size of the grains. The optimum grain size was shown to be 1.7-2.2 $\mathrm{mm}$.

An important point is that these grains can be obtained without the stage of growing single crystals of high perfection [13]. This does not only greatly decrease the costs of grain preparation, but also allows creating scintillators on the basis of substances which cannot be grown from the melt as single crystals by ordinary means. As an example, one can consider scintillation signals as function of alpha-excitation energy for scintillators based on $o$-POPOP (Fig. 1). The scintillation amplitude spectra were obtained for irradiation by alpha-particles of different energies. The alpha-particles of different energies were obtained by 


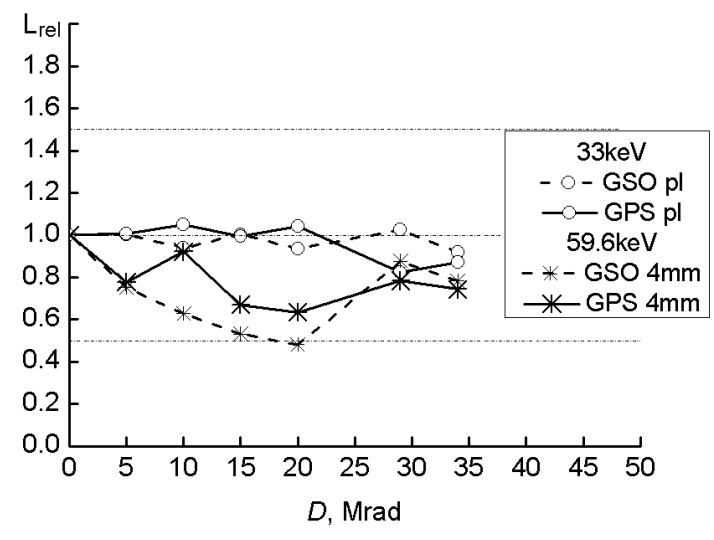

Fig. 2. Relative light output $L_{r e l}(1)$ of scintillators based on Ce:GSO and Ce:GPS (dashed black line and solid grey line, respectively) for different integrated radiation doses $D$. The value $L$ for $D=0$ (before irradiation) is taken for unity. Values of $L$ for samples of up to $0.1 \mathrm{~mm}$ thickness obtained under irradiation by gamma photons of energy $E_{\gamma}=33 \mathrm{keV}$ (circles), and up to $4 \mathrm{~mm}$ thickness - under irradiation by gamma photons of energy $E_{\gamma}=59.6 \mathrm{keV}$ (double cross).

their moderation in air. The energy of alpha-particles passing through air layer of thickness $h$ was determined in the following way. Knowing the value of alpha-particle free path in air $r$, we find the residual free path $\Delta=(r-h)$, and then, using the reference data [5], we determine the energy corresponding to this residual free path $\Delta$.

It should be noted that dependences of the scintillation signal intensity on the alpha-excitation energy for composite scintillators based on stilbene and 1,4-diphenyl1,3-butadiene are essentially similar [3].

\section{Prospects for improvement of radioresistance of composite scintillators}

Radiation detectors used in accelerators of new generation, such as LHC CERN (Switzerland), are subject to very high dose loads. Thus, during 10 years of operation of CMS-detector the total dose reaches 10 Mrad at average dose rate of $1 \mathrm{Mrad} / \mathrm{year}$ or $\sim 100 \mathrm{rad} / \mathrm{h}$. This greatly increases the importance of high radiation stability of scintillators. To look for a solution to this problem, we carried out radioresistance studies of dielectric gels from different producers that could be used for creation of composite detectors with high radiation stability. The following samples were studied: Sylgard-184, Sylgard-186, Sylgard-527,

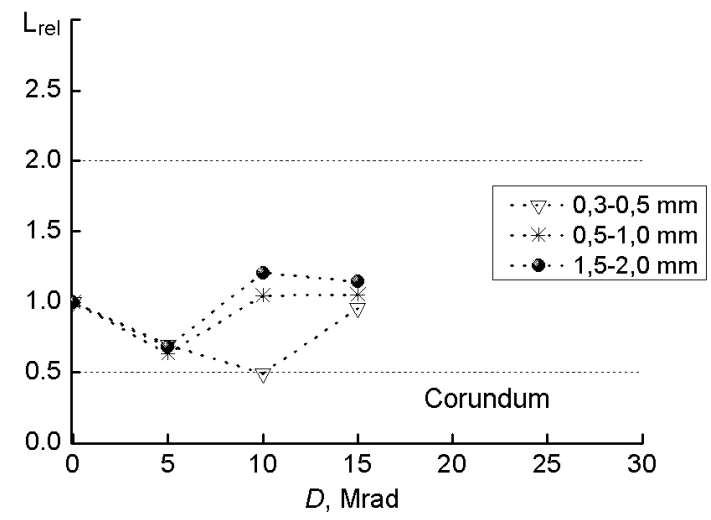

Fig. 3. Relative light output $L_{\text {rel }}(1)$ of scintillators based on $\mathrm{Al}_{2} \mathrm{O}_{3}$ activated by $\mathrm{Ti}$ for different integrated radiation doses $D$. The value $L$ for $D=0$ (before irradiation) is taken for unity. The grain size was varied within $0.3-0.5 \mathrm{~mm}$ (triangles), $0.5-1.0 \mathrm{~mm}$ (double crosses), 1.5-2.0 mm (circles). The value of $L$ obtained under irradiation by alpha-particles from ${ }^{239} \mathrm{Pu}$ source.

SKTN-med (viscosity $20 \mathrm{P}$ ), SKTN-med (viscosity $100 \mathrm{P}$ ), SUREL-SL-1. These dielectric gels can be used in a broad temperature range, they are not hygroscopic, do not react chemically with materials used in scintillation technologies, and they are transparent in the luminescence range of many scintillation materials. Sample irradiation was carried out on the electron accelerator at Kharkiv Physico-Technical Institute with electron energy of $\approx 9.2 \mathrm{MeV}$. The radiation dose rate was uniform during all the period of accumulation of integral doses, being equal to $0.23 \pm 0.01 \mathrm{Mrad} / \mathrm{h}$. The irradiation non-uniformity over the area where the samples were located did not exceed $5 \%$. The most promising from the viewpoint of mechanical and optical characteristics were Sylgard-184, Sylgard-186 [14].

Scintillators can be considered as radiation-resistant if under irradiation up to a certain dose $D$ the ratio of a certain basic parameter $A_{D}$ after irradiation to its initial value $A_{0}$ before irradiation varies by less than two times [15]. I.e.:

$$
A_{D} / A_{0} \leq 0.5 \text {. }
$$

We will use the criterion (1) for values of the relative light output $L_{r e l}$.

To check the possibility of using composite scintillators at high radiation dose loads, we prepared scintillators on the basis of Ce:GSO and Ce:GPS, with diameter $17 \mathrm{~mm}$ and height $4 \mathrm{~mm}$ (size of grains was varied 
within $0.5-2.0 \mathrm{~mm}$ ) and single-layer composite scintillators with grain sizes $L$ from 0.3 to $0.5 \mathrm{~mm}$. We have also prepared three single-layer composite scintillators on the basis of $\mathrm{Al}_{2} \mathrm{O}_{3}$ activated by $\mathrm{Ti}$ (grain sizes varied from 0.3 to $0.5 \mathrm{~mm}$, from 0.5 to $1.0 \mathrm{~mm}$, from 1.5 to $2.0 \mathrm{~mm}$ ). As a base, we used radiation-resistant dielectric gel Sylgard-184.

Fig. 2 shows the results of measurements of the relative light output $L_{r e l}(1)$ for composite scintillators based on single crystalline grains of GSO and GPS. Fig. 3 shows the relative light output $L_{\text {rel }}$ (1) data for composite scintillators on the basis of $\mathrm{Al}_{2} \mathrm{O}_{3}$ activated by $\mathrm{Ti}$.

As it can be seen from Fig. 2 and Fig. 3, the developed composite scintillators show high scintillation characteristics, evidencing sufficiently high radioresistance of these samples at the present stage of studies. These results are rather promising, though they are still preliminary, and further studies of such objects are needed, including conditions of high radiation loads.

\section{Conclusions}

The results obtained suggest that a methodological approach has been developed to creation of composite scintillators with characteristics that can be purposely modified for different tasks of radiation detection. Classical scintillation materials (single crystals, plastics, liquids, glasses) are characterized by two groups of parameters for property variation depending on the task. They are volume (accounting for shape) and chemical composition. A third parameter appears for composite scintillators - grain size. The overall scintillator size ensures efficient detection of primary radiations. The grain size allows, in a practically independent manner, "tuning" of the scintillator for efficient detection of secondary radiations.

Acknowledgements. This work was supported by the State Fund for fundamental research of Ukraine (project No.F58/06, "The effect of large radiation doses on scintillation and optical properties of novel types of organic detectors").

Author would like to thank Prof. N.Z.Galunov for continuous interest in this work and useful discussion, O.A.Tarasenko for measurements of light output, O.Ts.Sidletsky and Prof. L.A.Litvinov for providing single crystal samples, as well as a group from KPTI led by Prof. P.V.Sorokin for experiments in sample irradiation and primary express-analysis of their properties after irradiation.

\section{References}

1. Ukraine Patent (2009).

2. Ukraine Patent (2011).

3. N.L.Karavaeva, Probl. Atomic Sci. Technol., Ser.: Nucl. Phys. Invest., No.5, 91 (2014).

4. O.A.Tarasenko, N.Z.Galunov, N.L.Karavaeva et al., Radiat. Meas., 58, 61 (2013).

5. O.F.Nemets, Yu.V.Gofman. Handbook of Nuclear Physics, Naukova Dumka, Kiev (1975) [in Russian].

6. N.Z.Galunov, B.V.Grinyov, N.L.Karavaeva et al., IEEE Trans. Nucl. Sci., 56, 904 (2009).

7. N.Z.Galunov, B.V.Grinyov, J.K.Kim et al., J. Nucl. Sci. Technol., 5, 367 (2008).

8. N.L.Karavaeva, O.A.Tarasenko, Functional Materials, 16, 92 (2009).

9. N.Z.Galunov, B.V.Grinyov, N.L.Karavaeva et al., IEEE Trans. Nucl.Sc., 58, 339 (2011).

10. J.Haruna, J.H.Kaneko, M.Higuchi et al., in: Proc. IEEE Nuclear Science Symp. Conf. Rec., Oct.28-Nov.3, Havaii, USA (2007), p.1421.

11. Handbook of Radioactivity, 2nd ed., Elsevier Science, USA (2003).

12. N.L.Karavaeva, N.Z.Galunov, E.V.Martynenko et al., Functional Materials, 17, 549 (2010).

13. Ukraine Patent (2008).

14. A.Yu.Boiaryntsev, N.Z.Galunov, N.L.Karavaeva et al., Functional Materials, 20, 471 (2013).

15. N.Z.Galunov, V.P.Seminozhenko. Theory and Application of Radioluminescence of Organic Condensed Media, Naukova Dumka, Kiev (1997) [in Russian]. 